\title{
Epidemiologic Data on Heart Disease in the Orient*
}

\author{
Mariano M. ALIMURUNG, M. D., F.A. C. G.**
}

$I^{\mathrm{N}}$ 1940, Dr. Paul D. White wrote in his book, "Heart disease is a world problem, as much as is tuberculosis or dysentery or influenza, but it has not yet been investigated as such, in contrast to many of the infectious diseases which have scourged the world, especially in the form of waves of devastating epidemics."

Twelve years later, after his first visit to the Orient, Dr. White found the confirmation to his earlier statement. In his message to the inauguration of the Philippine Heart Association then, he said, "Heart disease, without any doubt, is one of the most serious, perhaps the most threatening malady of our times, not only in the Western world but also in the East.... Contrary to old ideas, rheumatic heart disease, hypertension, and coronary heart disease were common in those countries even though their true prevalence has been somewhat masked by the high incidence in the past of infectious disease and faulty nutrition."

By 1954 at the Second World Congress of Cardiology, cardiovascular epidemiology was an established subject of interest and of vital importance, as a number of papers on statistical data from various parts of the world were presented. Since then, this phase of cardiovascular research has received increasing impetus and encouragement. This is seen quite tangibly in this Tenth Pacific Science Congress as we discuss here today this problem.

Cardiovascular statistical data in the Orient is far from being complete. There is the obvious difficulty that such a type of investigation must face in the so-called underdeveloped countries where facilities for research and health data are necessarily inadequate, if not unreliable. Fortunately, epidemiologic data have been gradually gathered through the personal efforts of a number of investigators in India, the Philippines, Japan, Singapore, China, and Malaya, and there may be more, available

* Presented at a symposium on Diet and Vascular Disease at the Tenth Pacific Science Congress held in Honolulu, Hawaii, U.S. A., August 21 to September 6, 1961.

** Associate Professor of Medicine and Chief of Cardiovascular Section, Department of Medicine, Faculty of Medicine, Santo Tomas University, Manila; and Chief of Clinics and Cardiology, Santo Tomas University Hospital, Manila. 
or forthcoming. It is from these sources that we have gathered information for our purposes in this symposium. It is hoped that these data will give us, at least, some points of departure and basic information on the magnitude and features of cardiovascular disease in this part of the globe.

\section{Heart Disease in India}

It appears from the literature that the epidemiology of heart disease has been more extensively surveyed in India. There are data reported from seven large Indian cities, namely, Madras, Bombay, Amritsar, Lucknow, Calcutta, New Delhi, and Agra.

Estimation of true incidence of heart disease is a most difficult thing to achieve with accuracy; hence, most of the information is based on hospital figures. Even in the latter, there is noticeable variation. Thus Padmavati in New Delhi reported an incidence of 1.7 per cent against Mathur's 7.7 per cent in Agra, based on hospital figures. Padmavati calls attention to the incidence figures in the various social groups (rural, industrial, and high-income) because of their greater reliability based on more careful studies done on these individuals as compared with the low-income group.

From the seven cities just mentioned, it is evident that in India rheumatic heart disease constitutes the most frequent etiologic type. This includes the pattern in Bombay, since the apparently higher figure of 33.2 per cent in Vakil's figures assigned to a combined group of hypertensive and coronary heart disease would actually be lower than that of rheumatic heart disease, 24.8 per cent, if the hypertensive is separated from the coronary type. In Calcutta, however, Sinha found a slightly higher incidence of hypertensive heart cases, 29 per cent, over the rheumatic cases, 24.7 per cent. Other than these, the rest of India definitely faces rheumatic heart disease as the most frequent etiologic type. In fact, a recent report by Devi Chand from the Himalayan ranges in Simla disclosed a frequency of 50.6 per cent of rheumatic heart disease among the total number of cardiac cases examined.

Vakil in Bombay and Sinha in Calcutta reported a female predominance of 1.9 to 1 male among their rheumatic cases. On the other hand, Mathur found a male dominance of 2.4 to 1 female among his cases in Agra. The exact explanation of this difference in sex predominance in different parts of India is not clear.

Hypertension apparently is also a relatively frequent cause of heart disease in India. This is a bit contrary to previous concepts expressed by Western authors on the infrequency of hypertension in Oriental 
countries, chiefly in India and China. Moreover, as Sen Gupta reports, in Calcutta alone it seems that hypertension is on the increase, since the incidence of hypertensive heart disease in said city was 7.8 per cent in 1931 and had risen to 18.3 per cent by 1935 . Vakil actually found 29 per cent of his cardiac cases due to hypertension. Male dominance is a common finding. Mathur stresses the observation that in India, the most frequent complication of hypertension is cardiac involvement, not cerebral. As an over-all problem, it appears that hypertensive heart disease is the second major cardiac problem in India.

Undoubtedly, coronary heart disease is the chief object of interest in world cardiology today. India does have its own respectable share in this malady, ranging all the way from 10 to 28.3 per cent, as the various reports are analyzed and as hospital and private cases are viewed separately. Moreover, Mathur finds an increasing frequency of coronary heart disease in more rccent years. Mathur surveyed 1,803 unselected persons above 20 years of age from different socio-economic groups in Agra and found an incidence of 1.6 per cent of coronary heart disease, with its highest rate ( 3.8 per cent) among those in the high socio-economic group. Padmavati made the prediction statement that "India has the lowest incidence of coronary artery disease in the world." She also reported that women with degenerative heart disease suffer more from congestive heart failure than from acute myocardial infarction.

Cor pulmonale is a major form of heart disease in India, with an incidence ranging between 10 and 20 per cent. Despite some variation in the figures from different areas, the general conclusion remains the same; namely, the prominence of pulmonary heart disease in India. Males and females are equally affected. Chronic bronchitis with emphysema was attributed to be the leading pulmonary condition in these cases, and thus Padmavati stresses the role of inadequate medical facilities and poverty as important factors in contributing to the high rate of untreated respiratory infections.

Cardiovascular syphilis, previously reported by Vakil in 1949 as constituting 12.9 per cent of all etiologic types, is now a better controlled problem. More recent surveys have disclosed only 2.3 per cent of syphilitic heart disease in the series of Mathur in Agra and as low as 0.7 per cent in Padmavati's report. This is, of course, a gladdening development and its explanation is obvious.

Vakil pointed out two observations apparently bearing on racial group distribution of heart disease in India. First of all, he noted a relatively higher incidence of heart disease among Christians, Parsees and Jews than among the Hindus. Then, he also found syphilitic heart disease more frequent among Moslems, hypertensive and coronary types more 
common among the Christians and the group of Parsees and Jews.

\section{Heart Disease in the Philippines}

The Philippines is another country where an insight of the growing importance of heart disease has been recently obtained. The 7-years survey we did in Manila's four teaching general hospitals, with a total of 67,826 case records reviewed, disclosed an average annual rate of cardiac admission into the medical services of 13.8 per cent, 2 per cent into the pediatric services, with an over-all percentage of 8 per cent of all admissions into these two major services. The increasing prevalence of heart disease is seen from the rise of 10.8 to 17.1 per cent among hospital admissions from 1947 to 1953.

The major cardiac problem in the Philippines is rheumatic in nature, accounting for 46.6 per cent in the medical group, 54.9 per cent in the pediatric group, and 47.1 per cent in the combined series of cardiac patients. Like the situation in India, this prevalence of rheumatic heart disease in the Philippines is a clear evidence that this disease is certainly not a rarity in the tropics as had been previously thought of. Rather, it is felt that the frequency of streptococcal infections, chiefly among the lower income group of people in these countries, coupled with varying degrees of malnutrition and the debilitating effects of other infectious disease must be the favorable environment for the onset of rheumatic infection. Even in the studies of White in New England, which indicate a marked reduction of prevalence of rheumatic heart disease in a twentyfive year period, clearly suggests that improvement in social and living conditions must be the chief factor in such a decline.

Although still lower in frequency than in Western countries, hypertensive and coronary heart disease do occur to a significant degree among Filipinos. At least in this survey of hospital cases, hypertension was the etiology in 17.2 per cent and atherosclerosis in 15.5 per cent of heart disease. The elder Filipino internists express the observation that these two types of heart disease are much more frequent now than prior to last World War. The exact implication of this observation is not clear but certain suggestions can be entertained, to include changes in dietary and living habits, particularly in the metropolitan areas.

Cor pulmonale, as in India, comprises a significant sector in the spectrum of heart disease in the Philippines, accounting for 4.2 per cent in the survey referred to. A more recent review we made in the Santo Tomas University Hospital actually revealed an even higher prevalence of 8.9 per cent. The latter study of 59 cases with a total of 82 hospital admission disclosed that the leading primary lung condition, as far as 
they could be ascertained clinically in 31 and with postmortem findings in 19, were bronchial asthma in 57 per cent of the cases and pulmonary tuberculosis in 25 per cent. Of some interest is the early development of the condition in some instances, as it was found in four children (aged 1 year and 7 months, 3 years, and two of 11 years). These four children in our own series were found to have generalized tuberculosis. Also quite frequently among young subjects is the report by Pardo de Tavera and Stransky of pulmonary schistosomiasis as the background of the cor pulmonale.

Pari passu with progress in diagnosis and therapy is the relative prominence of congenital heart disease as it is seen today in the Philippines. Better recognition of the congenital anomalies, rather than actual increased incidence, must be the cause of this prominence of congenital defects. On the other hand, syphilitic heart disease is practically non-existent; beri-beri heart disease is most difficult to find now; and bacterial endocarditis is less frequent.

\section{Heart Disease in Japan}

In Japan, like in most countries, the increasing number of cardiovascular diseases has caused major alterations in the over-all picture of health problems and mortality rates. Tuberculosis, the leading cause of death in 1950, fell to sixth place by 1957 . Pulmonary diseases, such as pneumonia and bronchitis, and alimentary tract diseases, such as gastritis and enteritis, which were the most important causes of death in the early part of the 20th century, decreased sharply after World War II and now occupy the fifth and ninth places, respectively. On the other hand, deaths from vascular lesions of the central nervous system are now at the top of the list whereas cardiac deaths are third, with a tendency to a progressive annual increase.

The total number of deaths by heart disease was about 40,000 in 1948 and has increased at a rapid rate to a point where it exceeded 60,000 by 1957 . The rate to the total deaths was only 3.4 per cent in 1935 but rose to 8.6 per cent in 1958 .

As Ueda and Sugiura point out, an accurate evaluation of this increasing death rate by heart disease requires a detailed analysis. The recent changes in death rate indicate that the observed increase in death rate from heart disease is due mainly to the increased number of deaths from arteriosclerotic and degenerative heart disease.

When compared with data from Western countries, the higher rate of vascular lesions of the central nervous system and the lower incidence of heart disease in Japan are apparent. Rheumatic heart disease is 
somewhere in between that in the United States and England and that in France. Arteriosclerotic and degenerative heart disease is far less than in the United States and England, and nearly equals that of France.

A recent study by Okuni and associates at the Pediatric Clinic of the Tokyo University Hospital revealed that the incidence of rheumatic heart disease in Japan is increasing annually, contrary to the observation in Western countries. Based on 199 rheumatic "attacks" in 184 cases, the survey disclosed the following: (1) the disease occurs most often in spring and autumn; (2) the first attack is frequently between the age of 5 and 12 years; and (3) 90 per cent of patients have a latent type of carditis with a very high incidence of residual cardiac damage.

Coronary heart disease in Japan has been the object of continuing study since 1956. At the time, the comparative data obtained by the visiting group of White, Keys and Bronte-Stewart, the group of Kimura at Fukuoka, and the Honolulu study of Larsen disclosed a number of interesting findings: (1) the coal miners had less fat in their diet and less cholesterol in their blood than did the doctors in Japan, while the Japanese in Hawaii and California had more of each than did their former fellow citizens in Japan; (2) coronary thrombosis is more common in Tokyo and Kyoto than farther south in Fukuoka, but it is everywhere much less common ( $0.6 \%$ in Kyushu Univ.) than in the U.S.A. (18-30 per cent); (3) the Japanese in the Kuakini Hospital had more coronary thrombosis ( 4.9 per cent) and at younger ages than did the Japanese in Fukuoka ( 0.6 per cent); (4) the average diet of the Japanese men in Fukuoka contained 7 per cent of fat, chiefly of vegetable oil, whereas the Honolulu diet is much richer in fat and includes animal fat; and (5) in Japan the number of patients with coronary disease taken care of outside the large general hospitals is very much less than that obtaining in private practice in Hawaii.

A statistical review published in the Japanese Circulation Journal 1957, undertaken by the Committee on the Coronary Circulation sponsored by the Ministry of education in Japan, reviewed data from universities and medical schools from 1936 to 1954. One fact of interest is the remarkable increase of cases with myocardial infarction and patients with angina in 9 clinics of Japan's five large districts. The same was true with the total number of cardiac patients in general, a slight drop was noted during the war, 1942 to 1945. Although this recent increase is partly due to improved methods of diagnosis, the authors of this survey feel that an increase of coronary heart disease in Japan is an actual phenomenon.

The recent findings of Kimura on the atherosclerosis problems as it involved two groups of population, farmers and fishermen, in Japan are 
of some interest. Fishermen, in general, are better nourished, with larger intakes of total calories, protein, fats, carbohydrates, minerals and vitamins. On the other hand, coronary heart discase occurred more frequently (2.6 per cent) in farmers than in the fishermen (1.6 per cent). The exact interpretation of these data needs further scrutiny.

\section{Heart Disease in Malaya}

Muir from the University of Malaya has various data in the literature based on postmortem reviews. He found coronary heart disease at the top of the list in his postmortem material, 21.2 per cent, followed by hypertensive heart disease, 16.9 per cent, congenital, 16 per cent, and miscellaneous types, 15 per cent. Two other facts are worthy of mention. First is the relatively low prevalence of only 8.3 per cent of autopsied cases due to rheumatic heart disease. On the other hand, syphilis was found in 10.3 per cent of autopsied cardiac, cor pulmonale in 5.8 per cent, and beri-beri in 4.2 per cent.

In subsequent papers, Muir studied in greater detail the major types of heart disease. His findings in the field of congenital heart disease are rather striking. Indeed, not in many surveys does congenital heart disease appear as accounting for 2.25 per cent of all necropsies and for 16 per cent of all cardiac deaths. Indeed, in 1958 alone, he found 8.4 per cent of the total number of necropsies on children under the age of 10 years as having congenital cardiac malformations, next only to bronchopneumonia and gastroenteritis. This is despite the fact that the stillbirth rate in Singapore is low. Certainly the exact background of this prominence of congenital heart disease in Singapore is worthy of further study.

In so far as coronary heart disease is concerned, Muir's findings seem to corroborate the fact that the Chinese element of the population (which is the major element) is very much less liable to have the disease than the Indian, Indian Muslim, Eurasian, and European communities. For some food for thought, Muir made mention of the average diet of most Chinese in Singapore-based mainly on rice, with the food being cooked in peanut oil and only rarely in pig lard, and with fish as the staple source of protein. The other population sectors take more animal fat, more milk and eggs, and cook more with coconut oil.

In 1959, Danaraj and co-workers, also of the University of Malaya, studied the ethnic group differences in coronary heart disease in Singapore. They pointed out the same observation in that coronary heart disease is infrequent among Chinese (10.1 per cent) than among Indians (50 per cent) as revealed by postmortem findings. These authors submit the Singapore population as of possible importance in coronary research, 
considering the presence here of at least two major ethnic groups, with different cultural characteristics, but living under the same physical environment, and with remarkably different prevalence rates of coronary heart disease.

\section{Heart Disease in China}

Wan and co-workers reported in 1957 that rheumatic heart disease accounts for about one third (33.7 per cent) of all cardiovascular cases among adults in North China. Below the age of 40, rheumatic heart disease is the leading etiologic type, 49.5 per cent.

Unfortunately, we do not have in our hands right now more literature reference of recent date on heart disease in China. If the Singapore observations can be referred to in this regard, we can say that coronary heart disease is truly of low prevalence among the Chinese. Shapper, as early as 1941, emphasized the rarity of coronary atherosclerosis in North China, believing this to be due to a low intake of fats containing saturated fatty acids. Tung, in 1948, reported on 18 cases of coronary thrombosis and remarked that up to that time no paper on coronary disease in Ghina had been published. Incidentally, 15 of his patients came from the upper social and economic strata of Shanghai and thus the possibility that a higher intake of richer foods was mentioned. Foster in 1930 noted the rarity of arteriosclerosis in patients at the Yale-Hunan Hospital and found only one case of angina pectoris in 4,000. Incidentally, he noted the low blood pressure of the local population and found that the blood pressure of Americans living there gradually fell, too. On the other hand, Houston in 1928 noted that the blood pressure of immigrant Chinese in America rises.

A study among Chinese in Manila was conducted in 1956 of patients admitted to the Chinese General Hospital from 1950 to 1954 . We found heart disease in 7.3 per cent of all admissions and 21.6 per cent of all hospital deaths. In contrast to Filipino patients, wherein coronary heart disease was noted in 15.5 per cent, this disease was found in only 9.5 per cent among the Chinese patients. Likewise, rheumatic heart disease occurred only in 18.3 per cent, contrasted to the high incidence of 47.1 per cent among the Filipinos. On the other hand, hypertensive heart disease topped the list among the Chinese, 30.6 per cent, this being the case in 17.2 per cent of Filipino cardiacs.

\section{Comments and Summary}

Admittedly the various studies just referred to do all have their own 
inherent limitations, and would not necessarily represent the true extent of heart disease in the Orient, they may, nonetheless, give us sufficient insight as to characteristics of the heart problem in these areas.

Some of the interesting observations include the following:

(1) The prevalence of rheumatic heart disease in the Philippines, India, and China.

(2) The low coronary prevalence in Japan as a whole as well as among Ghinese and Indians.

(3) The prominence of cor pulmonale, particularly in India and Malaya, and to a certain extent in the Philippines.

(4) The unusually high frequency of vascular lesions in the brain, as the major cause of mortality in hypertension, in Japan.

(5) The rather high frequency of congenital heart disease observed in postmortem material in Singapore.

In addition, within the same area, the following observations deserve further mention:

(1) In Japan, there are varying degrees of prevalence of coronary heart disease, bit being higher in Tokyo and Kyoto than in Fukuoka.

(2) In Singapore, the same disease is more frequent among Indians, Indian Muslims, Eurasian and Europeans than the Chinese in the same area.

(3) In Manila, hypertension, as a cause of heart disease among hospital cases, is found more often in Chinese paticnts than among Filipinos; whereas the latter are apt to be more of the rheumatic types. Coronary disease occurs more frequently among Filipinos than among Chinese in Manila.

(4) In India, heart disease is more common among Christians, Parsees and Jews than among the Hindus, with syphilitic heart disease more frequent among Moslems and bypertensive and coronary types more conmon among Christians, Parsees and Jews.

Undoubtedly, this spectrum of heart disease in the Orient deserves further scrutiny, investigation and exploration. Whether differences are ethnic, cultural, and religious, dietary, environmental, etc., these factors have to be studied more extensively and intensively in order to arrive at some definitive conclusions. In the mean time, these data must serve us all as information and inspiration for future work. 